\title{
APLICAÇÃO DA METODOLOGIA DO PROGRAMA DE CONSERVAÇÃO DE ÁGUA NO MEIO URBANO, ENFOCANDO 0 REÚSO DA ÁGUA
}

\section{Application of the Methodology of the Water Conservation Program in the Urban Area, Focusing on Water Reuse}

\author{
Adriana Malinowski ${ }^{1}$ \\ Daniel Costa dos Santos ${ }^{2}$
}

\section{Resumo}

Este trabalho apresenta a estrutura básica do Programa de Conservação da Água no Meio Urbano e uma aplicação prática, enfocando ações de reúso de água em bacias hidrográficas. A respectiva aplicação se restringe ao entomo de duas estações de tratamento de esgoto, nas quais são avaliadas ações de reúso de água, especificamente esgoto tratado, voltadas ao atendimento dos setores industrial, agrícola e urbano. Em tal aplicação, observou-se que a manutenção da vazão ecológica do Rio Iguaçu, relacionada ao reúso indireto planejado, mostrou-se mais atraente, favorecendo a melhoria da qualidade de sua água e de comunidades a jusante. Aquelas ações relacionadas ao reúso direto se encontram em segundo plano, o que pode ser entendido como função, tanto dos custos elevados de implantação das ações de reúso direto, quanto dos benefícios relativamente reduzidos como, por exemplo, os menores volumes de água economizados na captação dos mananciais, que aqueles observados nas ações de reúso indireto planejado.

Palavras-chave: Sistema de apoio à decisão; Método AHP; Recursos hídricos.

\section{Abstract}

This work presents the basic structure of Water Conservation Program in the Urban Area, as well as a practical application of it, focusing actions of water reuse. The respective application was made in the surroundings of the two wastewater treatment stations. In such application, it was observed that the improvement of the water quality in the Iguaçu River, related to the planned indirect water reuse, showed more attractive, favoring the improvement of water quality and the downstream communities. Those actions related to the direct water reuse remained in second plan. The reason for that can be assumed as the high costs of the infrastructure, as well as relatively low beneficial, as small amount of water volume saved from water source, as compared to those observed in the planed indirect reuse.

Keywords: Decision support system; Method AHP; Water resources.

1 Mestranda do Programa de Pós-Graduação em Engenharia dos Recursos Hídricos e Ambientais da UFPR. E-mail: adriana.malinowski@ig.com.br.

2 Docente Adjunto da Universidade Federal do Paraná. Departamento de Hidráulica e Saneamento. Programa de Pós-Graduação em Engenharia dos Recursos Hídricos e Ambientais. E-mail: dcsantos.dhs@ufpr.br 


\section{Introdução}

A sociedade tem hoje, inegavelmente, uma relação dualista com o Recurso Água, pois é necessário universalizar o acesso à água e, ao mesmo tempo, promover a sustentabilidade dos recursos hídricos. É notório que uma parcela significativa da população brasileira não tem acesso à água potável e, por outro lado, reconhece-se a realidade da exaustão dos recursos hídricos naturais, seja pelo crescente consumo de água, ou pela crescente deterioração de sua qualidade. Logo, cabe ressaltar o grande desafio que se estabelece: como atender à crescente demanda da universalização do acesso, quando o próprio insumo em questão tende à escassez? Dada essa condição, surgem o planejamento e a gestão dos recursos hídricos como premissas fundamentais a serem consideradas, os quais contemplam questões relacionadas à adequação entre disponibilidade e demanda qualiquantitativa. A disponibilidade é função das condições naturais, enquanto que a demanda é relativa aos usos na infra-estrutura sanitária, agricultura, indústria, geração de energia elétrica, navegação fluvial, recreação, entre outros. Observa-se que tais usos múltiplos dos recursos hídricos requerem uma integração harmoniosa, de maneira a evitar possíveis conflitos, maximizar vantagens e minimizar desvantagens.

Admitindo-se como conceito de Conservação de Água um conjunto de ações de economia e proteção dos recursos hídricos, é objetivo deste trabalho apresentar uma aplicação da metodologia contida no Programa de Conservação da Água no Meio Urbano (PCA), a qual possibilita a estruturação de diretrizes para o planejamento de ações de conservação de água. Este trabalho apresenta, enquanto objetivo específico, uma aplicação do PCA especificamente voltada para ações de reúso de água em bacias hidrográficas.

Destaca-se que o PCA prevê o planejamento e a gestão integrada de ações, no intuito de possibilitar a conservação da água em seus aspectos qualitativos e quantitativos. A conservação quantitativa considera ações de economia de água, como práticas respectivas ao uso racional, com o objetivo de reduzir desperdícios nas edificações e nos sistemas de abastecimento de água, além de práticas específicas de utilização de fontes alternativas, como o reúso de água a nível residencial, industrial e da própria infra-estrutura sanitária. A conser- vação qualitativa, importante para a manutenção da qualidade dos recursos hídricos, depende de ações de controle da poluição, como o tratamento de efluentes e do próprio reúso de água, uma vez que esta prática tende a reduzir o volume de efluentes normalmente lançados nos corpos receptores.

Com base nesta referência conceitual, 0 PCA é estruturado para atender a duas linhas de atuação: a conservação da água nas edificações e a na infra-estrutura sanitária. A linha de atuação respectiva às edificações corresponde ao Programa de Conservação da Água nas Edificações (PCAE), enquanto aquela referente à infra-estrutura pertence ao Programa de Conservação da Água na Infra-estrutura Sanitária (PCAI).

O PCAE objetiva o planejamento e gestão das ações de conservação da água nas habitações, por meio de hierarquização sob aspectos da viabilidade econômica, do benefício gerado e do risco sanitário associado. Já o PCAI, objeto de destaque neste trabalho, por prever ações de reúso de água nas bacias hidrográficas, apresenta estrutura similar ao PCAE, tendo como diferença básica o enfoque sobre a infra-estrutura sanitária. São previstas cinco etapas que objetivam a gestão do uso da água na infra-estrutura sanitária urbana, especificamente nos Sistemas de Abastecimento de Água e Sistemas de Esgotamento Sanitário.

A 1. a etapa objetiva caracterizar o cenário de interesse sob vários aspectos, tais como a identificação e descrição dos usuários, avaliação do perfil e da aceitabilidade do usuário, estimativa quali-quantitativa da demanda de água e a prospecção de relações entre o consumo de água e variáveis diversas.

A 2. ${ }^{\text {a }}$ etapa objetiva a caracterização das ações de conservação de água. O respectivo processo de caracterização ocorre em duas fases, primeiro pela concepção e seleção das ações de conservação de água e, posteriormente, pela caracterização das ações selecionadas.

A 3. a etapa trata da avaliação da aplicabilidade das ações de conservação de água. Tornase necessária a criação de um sistema que avalie a aplicabilidade das ações, em função tanto de requisitos quali-quantitativos impostos pelos usos previstos, quanto de uma análise da relação custobenefício-risco pertinente.

A 4. a etapa prevê o estabelecimento de uma hierarquização das ações de conservação de água. Assim sendo, são considerados os riscos acei- 
táveis, a viabilidade econômica, os níveis possíveis de conservação de água, a aceitabilidade pública, os graus de impacto ambiental e de benefícios previstos, entre outras variáveis. De posse destes dados é possível obter uma escala de prioridade, a qual pode facilitar ao gestor a implantação das ações em uma escala temporal. Para tanto, torna-se importante à utilização de ferramentas de Sistemas de Apoio à Decisão para o planejamento e posterior confecção do Plano de Conservação da Água no Meio Urbano. Neste sentido, o PCAI apresenta a Análise Multicritério como o Sistema de Apoio à Decisão referencial para a condução do processo de hierarquização. Tal escolha se fundamenta no fato de que esse tipo de análise trabalha com critérios de ordem qualitativas e mensuráveis quantitativamente.

Muitos são os métodos passíveis de utilização, cabendo destaque, aqui, o método AHP, o qual, segundo Bevilacqua e Braglia (2000), possibilita a apresentação de decisões de problemas complexos, considerando-se diversos fatores, sendo possível realizar julgamentos de fatores que não pertencem, necessariamente, ao gerente de manutenção, além de ser capaz de administrar um número elevado de alternativas, de modo eficiente. Sua estrutura prevê a construção de uma árvore hierárquica abrangendo a complexidade do problema. Com base na estrutura estabelecida, são criadas matrizes de comparação entre os elementos critérios, sub-critérios e ações. Saaty (1980) estabeleceu uma escala variando de 1 a 9 , referente a "importância igual" até "importância absoluta", respectivamente.

Enfim, a 5a etapa trabalha o planejamento e gestão da conservação da água, onde torna-se possível propor um planejamento otimizado que promova a economia esperada e garanta a segurança sanitária. Desta forma, o PCA prevê a organização de um conjunto de procedimentos que permitam a análise da aplicabilidade integrada das ações, da economia obtida e do risco sanitário associado. O resultado desta análise embasa, portanto, a confecção do Plano de Conservação da Água, o qual apresenta diretrizes para o gerenciamento de conservação da água no meio urbano, a partir das ações definidas hierarquicamente. No referido caso, existem três maneiras de se aplicar o PCA: 1) por meio da aplicação do PCAE, ou 2) enfocar apenas a infra-estrutura sanitária, por meio do PCAI, ou 3) aplicar ambos simultaneamente, obtendo-se resultados para a confecção do planejamento e gestão da conservação da água que considere a relação entre a habitação e o meio ambiente; é possível, por exemplo, avaliar o impacto de medidas de conservação da água nas edificações sobre a conservação da água nos mananciais.

\section{Material e métodos}

Segue a apresentação da aplicação do PCA, especificamente o PCAI, com ênfase nas ações de reúso da água. São estudadas as áreas entorno de duas estações de tratamento de esgoto: a ETE Santa Quitéria e a ETE Belém.

\section{1. a Caracterização da Área de Estudo}

A área de abrangência deste estudo é delimitada por raio de aproximadamente $10 \mathrm{~km}$ a partir das ETE's Santa Quitéria e Belém. A ETE Santa Quitéria está localizada na sub-bacia do Rio Barigüi e atende, de forma total ou parcial, a 08 bairros de Curitiba. Essa possui processo de tratamento anaeróbio, com reatores do tipo UASB, sendo que seis estão em funcionamento, dos oito previstos para final do plano. Seus efluentes são lançados no Rio Barigüi, aproximadamente a $40 \mathrm{~km}$ de sua foz. Fazem parte da área de estudo dessa ETE os municípios Araucária, Campo Largo, Campo Magro e Curitiba, onde encontram-se 41 indústrias diversificadas em suas funções, 38 áreas públicas, que passam pelo processo de limpeza usando água, dessas, 30 são ruas onde são realizadas feiras livres e 8 são praças ou calçadas transitadas por pedestres, que eventualmente as usam indevidamente como sanitário.

A ETE Belém está localizada na bacia do Alto Iguaçu, no bairro Boqueirão, próxima ao Parque Iguaçu. Possui processo de tratamento aeróbio, por meio da aeração prolongada em valor de oxidação tipo carrossel. Essa ETE atinge ótima qualidade no tratamento do efluente durante a maior parte do tempo, lançando-os no Rio Iguaçu. Fazem parte da área de estudo da ETE Belém os municípios de Curitiba, Pinhais, Piraquara e São José dos Pinhais, nos quais se acham estabelecidas 18 indústrias diversificadas em suas funções e 13 ruas, onde acorrem feiras livres. A Figura 1 apresenta a localização das áreas de estudo. 


\section{FIGURA 1 - Localização das Estações de Tratamento de Esgoto}

Figure 1 - Wastewater Treatment Stations localization

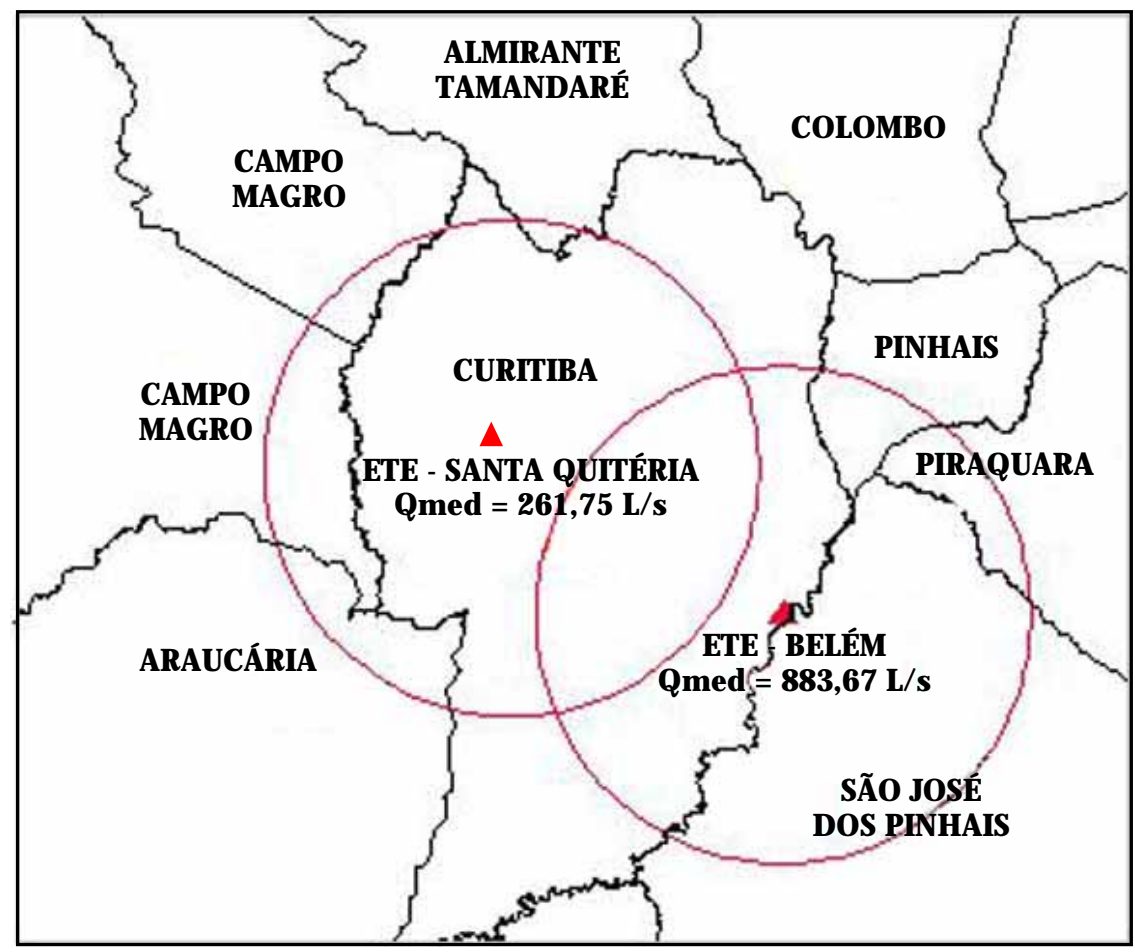

\section{2.- Caracterização das Ações de Conservação de Água}

Foram listadas 52 possíveis ações para as áreas que circunscrevem as duas ETE's. Após uma seleção, por meio da qual se levou em considera- ção a viabilidade técnica preliminar, as vazões de oferta e demanda, as distâncias entre os pontos de oferta e os possíveis usuários, nove foram destacadas. A Tabela 1 apresenta as nove ações selecionadas. 


\section{TABELA 1 - Relação entre ações realizadas, grupos atendidos, vazão (demanda) e água eco- nomizada no manancial.}

Table 1 - Relation between actions carry out, considered groups, flow (require) and saved water in water source.

\begin{tabular}{|c|c|c|c|c|c|c|c|}
\hline \multirow[t]{3}{*}{ Localização } & \multicolumn{3}{|c|}{ Ação Descrição } & \multirow{3}{*}{$\begin{array}{l}\begin{array}{l}\text { Grupos } \\
\text { Atendidos } \\
\text { (L/s) }\end{array} \\
\text { G10 } \\
\text { G11 }\end{array}$} & \multirow{2}{*}{$\begin{array}{l}\begin{array}{l}\text { Vazão } \\
\text { (demanda) } \\
\text { (demanda) } \\
\text { (L/s) }\end{array} \\
299,72\end{array}$} & \multirow{3}{*}{$\begin{array}{l}\text { Vazão } \\
\text { Total } \\
\text { no manancial } \\
\text { (L/s) } \\
330,57\end{array}$} & \multirow{2}{*}{$\begin{array}{l}\text { Água } \\
\text { Economizada } \\
261,75^{\mathrm{P}} \\
\end{array}$} \\
\hline & \multirow[t]{2}{*}{01} & \multirow[t]{2}{*}{ TRE1+A5+CR3 } & RD5 & & & & \\
\hline & & & CM7 & & 30,85 & & \\
\hline & 02 & \multicolumn{2}{|c|}{ TRE1+A1+CR1+RD6 } & $\mathrm{G} 12$ & 281,83 & 281,83 & $261,75^{\mathrm{P}}$ \\
\hline \multirow[t]{5}{*}{ Santa Quitéria } & \multirow[t]{2}{*}{03} & \multirow[t]{2}{*}{ TRE1+A1+CR1+ } & $\mathrm{RD} 1$ & $\mathrm{G} 1+\mathrm{G} 2$ & 330,57 & \multirow[t]{2}{*}{596,26} & \multirow[t]{2}{*}{$261,75^{\mathrm{P}}$} \\
\hline & & & CM8 & $\mathrm{G} 14$ & 265,69 & & \\
\hline & 04 & $\mathrm{AC}$ & & $\mathrm{G} 25$ & - & - & $356,38^{\mathrm{T}}$ \\
\hline & \multirow[t]{2}{*}{05} & \multirow[t]{2}{*}{ TRE1+A13+H9+ } & CM23 & $\mathrm{G} 18+\mathrm{G} 21(1)$ & 4,58 & \multirow[t]{2}{*}{59,09} & \multirow[t]{2}{*}{$59,09^{\mathrm{T}}$} \\
\hline & & & CM20 & G5 & 4,51 & & \\
\hline \multirow[t]{5}{*}{ Belém } & 06 & \multicolumn{2}{|c|}{ TRE2+A15+CR5+RD10 } & G27+G28+G29 (1) & 72,28 & 72,28 & $72,28^{\mathrm{T}}$ \\
\hline & 07 & \multicolumn{2}{|c|}{ TRE2+A15+CR5+CM22 } & $\mathrm{G} 27+\mathrm{G} 28+\mathrm{G} 29(1)$ & 72,28 & 72,28 & $72,28^{\mathrm{T}}$ \\
\hline & \multirow[t]{2}{*}{08} & \multirow[t]{2}{*}{ TRE2+A15+CR5+ } & CM25 & G33 & $1.224,82$ & \multirow[t]{2}{*}{$2.087,80$} & \multirow[t]{2}{*}{$441,83^{\mathrm{P}}$} \\
\hline & & & CM26 & G34 & 862,98 & & \\
\hline & 09 & \multicolumn{2}{|c|}{ TRE2+LD2+MVR+ MVQR+RI } & $\mathrm{MVQR+RI}=\mathrm{Q}_{\text {ecológica }}$ & 441,83 & 441,83 & $-(2)$ \\
\hline
\end{tabular}

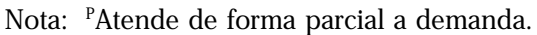

${ }^{\mathrm{T}}$ Atende de forma total a demanda.

(1) Atende incêndio e desobstrução de galerias, vazão estimada para estes usos $50 \mathrm{~L} / \mathrm{s}$.

(2) Não há economia no manancial, somente se está devolvendo a água residuária tratada a ele.

TRE1: Tratamento adicional e reservação na ETE Santa Quitéria; TRE2: Tratamento adicional e reservação na ETE Belém; Ai: adutora de número i. CRi: centro de reservação de número i; CMi: Caminhão de número i; Hi: Hidrante de número i; AC: Água Cinza; RD: Reúso Direto; RI: Reúso Indireto; LD: Lançamento direto; MVQR: Manutenção da vazão e qualidade do rio

Quanto aos grupos referentes às indústrias, abrangendo setores como o alimentício, papeleiro, cerâmico, etc., destaca-se que o grupo G5 é composto por 4 indústrias que distam, em média, aproximadamente 8,5 km da ETE Santa Quitéria e 8,0 km da ETE Belém, sendo a vazão de demanda desse grupo de 4,51 L s${ }^{-1}$. O grupo G10 é composto de 9 indústrias, distantes em média $10,0 \mathrm{~km}$ da ETE Santa Quitéria, e com vazão de demanda de 299,72 L s ${ }^{-1}$ O G11 conta com 16 indústrias distantes, em média, $11 \mathrm{~km}$ da ETE Santa Quitéria e tem como vazão de demanda 30,85 L s ${ }^{-1}$. Já o G12 é composto somente por duas indústrias, sendo que essas possuem como vazão de demanda 281,83 L $\mathrm{S}^{-1}$ e distam da ETE Santa Quitéria aproximadamente $12 \mathrm{~km}$. As ações 06 e 07 atendem ao mesmo pólo, composto por nove indústrias, formadoras dos grupos G27, G28 e G29. Cabe aqui esclarecer que foi considerada uma vazão de $50 \mathrm{~L} \mathrm{~s}^{-1}$ para atendimento, quando necessário, para ações de combate a incêndio e desobstrução de galerias.
Referente à limpeza pública de ruas, para a qual ocorrem feiras livres e praças ou calçadas usadas indevidamente como sanitário, o G18 compreende 8 ruas com feiras livres e 8 praças ou calçadas com distância à ETE variando aproximadamente 2,5 a $11,0 \mathrm{~km}$, cuja vazão de demanda prevista é de 4,53 L s${ }^{-1}$; já o G21 agrupa 10 ruas distantes 5,0 a 12,0 km da ETE Santa Quitéria, perfazendo uma vazão de demanda de $0,05 \mathrm{~L} \mathrm{~s}^{-1}$.

Para a agricultura, os grupos foram estabelecidos conforme os maiores produtores da região, por município. De acordo com o IBGE (2004), nestas áreas são produzidos arroz, feijão, milho, soja e trigo e tem-se previsão de demanda de vazões de água de reúso de 265,69 L s s${ }^{-1}$ para Araucária (G14), 1.224,82 $\mathrm{L} \mathrm{s}^{-1}$ para Curitiba (G33) e 862,98 Ls ${ }^{-1}$ para São José dos Pinhais (G34).

Para a ação denominada G25, uso de água cinza, considerou-se apenas a água proveniente do chuveiro e se adotou um tempo médio para banho de 10 min e uma vazão para o chuveiro de 
$15 \mathrm{~L} \mathrm{~min}^{-1}$, obtendo-se o consumo de 1.796,70 L/s (Lobato, 2005). Estabeleceu-se usar apenas 20\% desta vazão, pois se espera que, inicialmente, haja adesão aproximada nesta proporção da população, refletindo em economia de água retirada do manancial.

\section{3. - Avaliação da Aplicabilidade das Ações de Conservação de Água}

A aplicabilidade foi avaliada considerando-se o volume liberado pelas ETE's, o custo para implantação do sistema em função da distância e a vazão de demanda, o custo de transporte via caminhão, além da qualidade da água de reúso fornecida quando comparada com a qualidade exigida pelo uso. Apesar dos critérios da EPA se- rem mais restritivos que os da OMS, optou-se por adotá-los, uma vez que se considerou que o cumprimento de diretrizes mais restritivas pode favorecer a aceitabilidade perante os usuários, além de diminuir os riscos impostos pela prática do reúso de água. No entanto, espera-se que após a consolidação da prática do reúso de água, possa haver uma maior flexibilização dos critérios adotados.

\section{4. a Hierarquização das Ações de Conserva- ção de Água}

A Figura 2 apresenta a árvore hierárquica com as ações escolhidas e os critérios e subcritérios que farão parte da análise.

\section{FIGURA 2 - Árvore hierárquica, critérios e subcritérios realizados nas análises.}

Figure 2 - Hierarchic tree, criterion and sub-criterion carried out in the analysis.

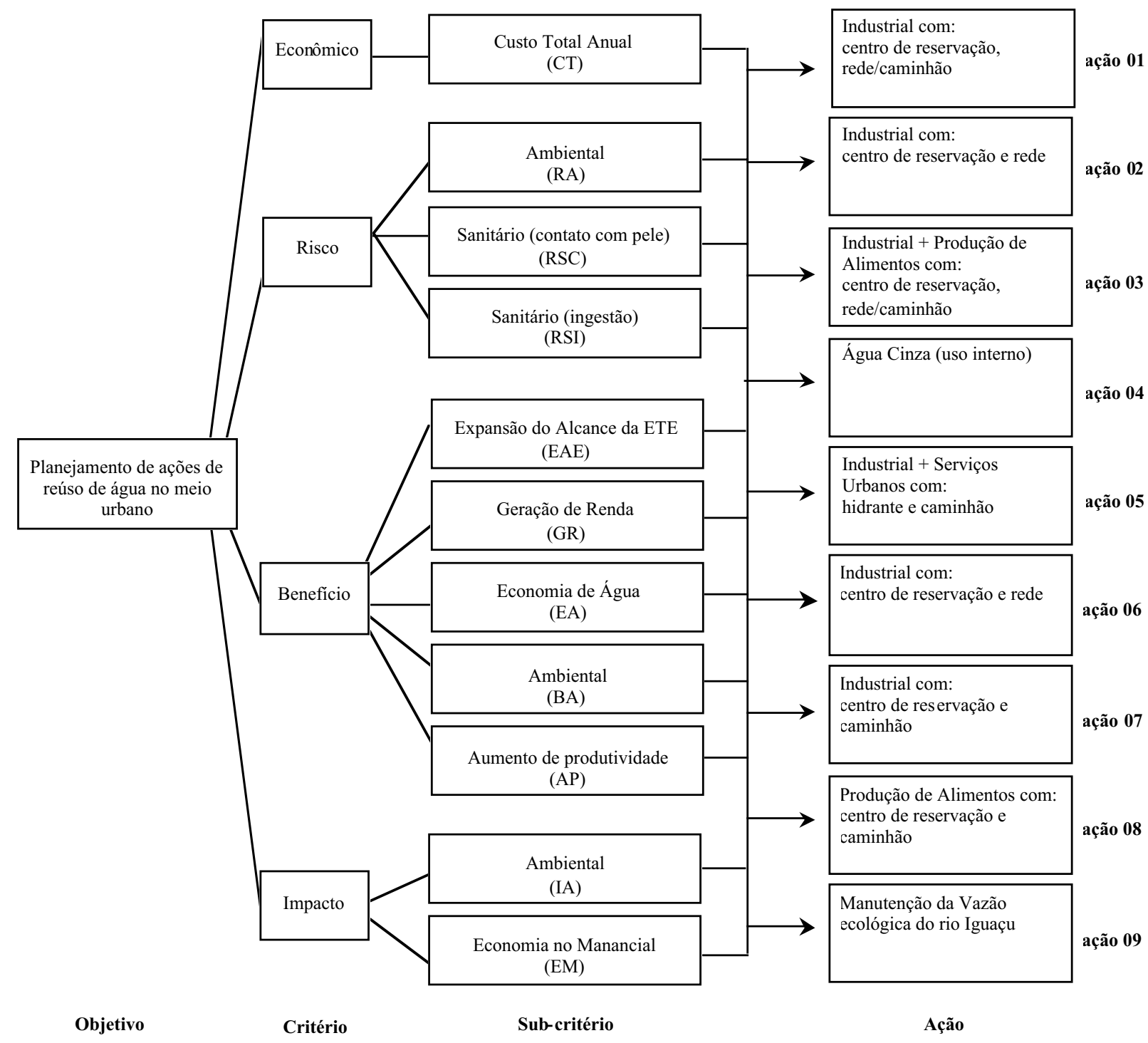


Quanto aos subcritérios, destaca-se que o custo total anual engloba os custos de implantação, manutenção e operação dos sistemas propostos de reúso de água. Referente aos riscos, o RSC refere-se ao contato direto da água de reúso com o corpo de pessoas, caso não sejam utilizados equipamentos de proteção como botas, luvas e óculos. O RSI considera a possibilidade de ingestão acidental, além de gotículas que poderão ser inaladas, devido à formação de aerossóis e, por fim, 0 RA avalia os riscos ambientais envolvendo a possível contaminação do solo, da água e do ar. Específico à EA, considera-se toda e qualquer economia que se possa fazer, substituindo-se a água potável pela água de reúso e, quanto ao IA, são consideradas as alterações ambientais que poderão ocorrer devido à disposição da água de reúso no meio ambiente, tais como a contaminação do solo, dos corpos hídricos, da fauna e flora, além da maior disponibilidade de água para fins mais nobres.

De acordo com a escala proposta por Saaty (1980), foi estabelecida a proposição dos pesos, variando de 0 a 9 . Cabe aqui esclarecer que os pesos envolvendo os critérios foram determinados pelos autores, enquanto que os demais foram estabelecidos pelas tabelas criadas, envolvendo as probabilidades de ocorrência e de conseqüência devido à ocorrência. Foram obtidos valores quantitativos para a análise do custo total anual, para o benefício devido à economia de água e para o impacto devido à economia de água no manancial.

\section{Resultados e discussão}

Aplicando-se o método AHP, obtevese a classificação das ações em ordem decrescente de importância. O Gráfico 1 apresenta a hierarquização destas ações.

\section{GRÁFICO 1 - Grau de prioridade das ações}

Graph 1 - Degree of priority of actions

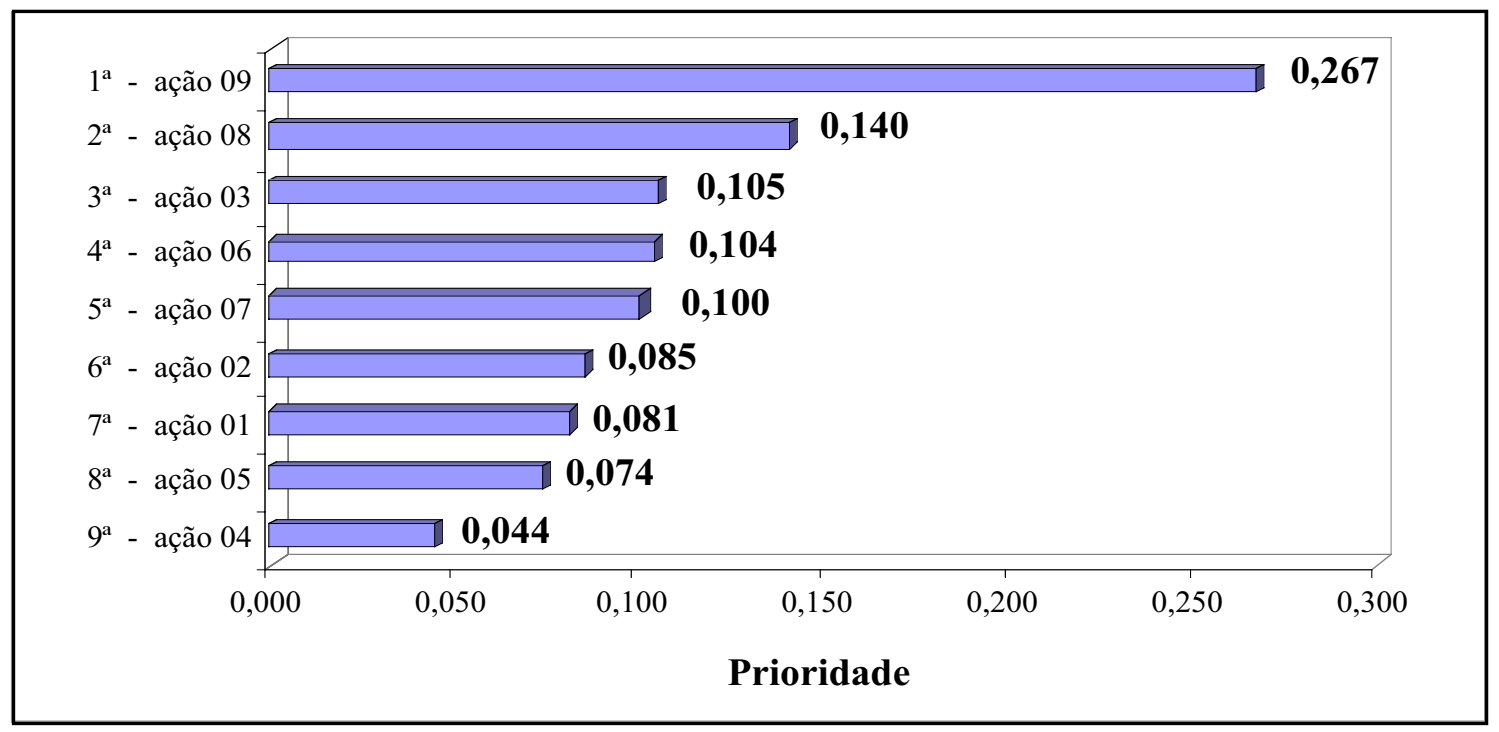

Segundo o Método AHP, o planejamento para implantação das ações de reúso de água poderia contemplar primeiramente ações próprias do reúso indireto planejado, como manutenção da vazão ecológica do Rio Iguaçu, favorecendo a melhoria da qualidade da água desse rio, tanto no aspecto ambiental, quanto no aspecto de potencializar usos à jusante do ponto de disposição do esgoto tratado. A seguir, encontra-se a ação que atende os usos agrícolas nas cidades de Curitiba e São José dos Pinhais. A ação 03 aparece na seqüência, novamente atendendo ao setor agrícola, município de Araucária e também atendendo às indústrias referentes aos grupos G1 e G2. Na seqüência aparecem as ações 06 e 07, atendendo ao setor industrial, por meio do uso de rede e caminhão, respectivamente. Essas ações diferenciaram- 
se apenas quanto ao risco ambiental, uma vez que seus custos foram muito próximos, não apresentando diferença representativa durante a aplicação do Método AHP. Na sexta e sétima posições aparece o setor industrial, sendo que a ação 02, com apenas duas indústrias, mostrou-se mais atrativa quando comparada com a ação 01, a qual continha 25 indústrias. Finalmente, em última posição, surge a ação referente ao uso de água cinza nas edificações ou de reúso direto, porém, voltada para a reciclagem (ação 04). Tal posição se deve, em muito, aos altos custos necessários à sua implantação, manutenção e operação.

\section{Conclusões}

\author{
1. Aplicando-se o PCA no Meio Urbano e \\ se adotando o Méto do AHP como sistema de apoio \\ à decisão, chegou-se a um resultado que possibili- \\ ta sugerir ações de reúso de água, caracterizá-las, \\ avaliar suas aplicabilidades e hierarquizá-las, for- \\ necendo, como resposta, uma proposta para im- \\ plementação dessas ações no meio urbano; \\ 2. Ações relacionadas ao reúso indireto \\ planejado mostraram-se mais atraentes, como a \\ manutenção da vazão ecológica do Rio Iguaçu e a \\ conseqüente promoção da melhoria da qualidade \\ da água, favorecendo as comunidades à jusante; e \\ 3. A aplicação do Método AHP facilitou o \\ acompanhamento das comparações das matrizes,
}

fornecendo resultados parciais, além de apresentar de forma simples valores que indicam a sua consistência, oferecendo ao decisor maior confiança aos valores atribuídos às matrizes de julgamento.

\section{Referências}

BEVILACQUA, N.; BRAGLA, M. The analytic hierarchy applied to maintenance strategy selection. Reliability engineering \& system safety, v. 70, p. 71-83, 2000.

IBGE. Área plantada, área colhida, quantidade produzida, rendimento médio e valor da produção de cereais, leguminosas e oleaginosas, segundo as mesorregiões, microrregiões e os municípios 2004. Disponível em

ftp://ftp.ibge.gov.br/ Producao_Agricola/ Producao_Agricola_Municipal_Cereais_Leguminosas _Oleaginosas/2004/. Acesso em: 01 out. 2005.

LOBATO, M.B. Sistema de hierarquização de ações de conservação da água em edificações com aplicação do método Electre III. 2005. $263 f$. Dissertação (Mestrado) UFPR. Curitiba, 2005.

SAATY, T. L Analytic hierarchy process. New York: McGraw-Hill, 1980. 